\title{
The Boomerang Paradox - Part II: policy prescriptions for reducing fuel poverty in Australia
}

\author{
Paul Simshauser, Tim Nelson and Thao Doan* \\ Level 22, 101 Miller Street \\ North Sydney, NSW, 2060. \\ April 2010
}

\begin{abstract}
A characteristic of advanced economies is continual growth in household income and plunging costs of electric appliances. In Australia, increases in household floor-space combined with power prices that are among the lowest in the world have resulted in rapid growth in peak demand. The power grid in turn requires substantial incremental generating and network capacity, which is utilized momentarily at best. As the cost of augmentation is gradually revealed, fuel poverty seems predictable. We call this the Boomerang Paradox; the nation's rising wealth has created the pre-conditions for fuel poverty. But appropriate and timely policy settings can defuse its effects.
\end{abstract}

JEL Codes: D24, D92, L11, L94 and Q41.

Keywords: Electricity Prices, Fuel Poverty, Carbon Tax.

\section{Introduction}

Australian residential electricity bills have historically been among the lowest in the world. In fact, in FY08 an electricity bill represented just $2.4 \%$ of household income ${ }^{1}$, a result underpinned by Australia's highly successful National Electricity Market (NEM) ${ }^{2}$ However, electricity prices in Australia are increasing due to a range of factors. In The Boomerang Paradox Part I, we provided detailed price forecasts for FY15 and contrasted these with prices in FY08 in the jurisdictions of NSW and QLD, two of the largest states in Australia.

There are four primary cost shocks that we analysed. First, Australia's great wealth of energy resources, which have historically been sold to energy utilities at a margin above extraction cost, are now being developed at such scale for export that they have a potential to link with global energy indices and may cause a fuel cost shock. Second, power plant costs surged materially over the past decade, as did the cost of capital following the FY09 global financial meltdown. Third, network infrastructure is now expanding at record rates to keep pace with rapidly rising peak loads. And finally, environmental demands of a comparatively wealthy developed economy have led to community demand for the tightening of performance standards which will cause a technology shift in power generation investments from very low cost coal to lower $\mathrm{CO}_{2}$ emitting gas, and increased higher cost renewable capacity via legislated targets, and potentially, the taxation of carbon emissions.

We called our scenario the Boomerang Paradox - rising wealth is driving substantial increases in household floor space and appliance use, causing non-trivial increases in peak energy demand. The power grid in turn requires vast amounts of incremental generating and network capacity which is utilized momentarily at best. As the cost of this augmentation is gradually revealed, we

\footnotetext{
* Paul Simshauser is the Chief Economist at AGL Energy Ltd and Professor of Finance at Griffith University’s Business School (psimshauser@agl.com.au). Tim Nelson is Head of Economic Policy \& Sustainability at AGL Energy Ltd, and Dr Thao Doan is a strategist in the Energy Trading Division at Stanwell Corporation Limited. The views expressed in this article are those of the authors and any errors or omissions remain the responsibility of the authors.

${ }^{1}$ Based on energy consumption data from DEEDI (2010), unit electricity costs as presented in Section 2 and median household income from the Australian Bureau of Statistics at http://www.abs.gov.au/AUSSTATS/abs@.nsf/DetailsPage/6523.0200708? OpenDocument.

${ }^{2}$ See for example IEA (2005) at p.14 for a discussion on the performance of electricity deregulation in the NEM.
} 
consider it predictable that fuel poverty will emerge in Australia for the first time amongst low disposable income households. ${ }^{3}$ Our modeling results indicate that when the variables outlined above conspire in the same direction, household electricity costs have the potential to rise from about \$130/MWh in FY08 to \$250-\$300/MWh in FY15 (depending on the scenario).

This article is structured as follows; Section 2 revisits the unit price projections outlined in The Boomerang Paradox Part I for NSW and QLD and summarises the conclusions of this analysis. In Section 3, we define fuel poverty as a construct within Australia. Importantly we contrast our definition with existing definitions in the Northern Hemisphere which are built around special heating loads rather cooling loads which are the predominant driver of peak demand in Australia. Section 4 outlines our estimates of NSW and QLD households that may be defined as experiencing fuel poverty in FY15 based upon the price projections outlined in Section 2. The policy implications of our analysis in relation to both social policy and energy markets are discussed in Section 5 and concluding remarks follow.

\section{Unit price projection for FY15 in Sydney and Brisbane}

In The Boomerang Paradox Part I, we provided detailed price projections for electricity in Sydney (NSW) and Brisbane (QLD) for FY15 and contrasted these with prices in existence in FY08 in the same locations. Given this analysis is detailed in this earlier paper; we do not intend to reproduce how the prices were derived here. However, it is worth retracing the drivers of higher prices: switching from coal to gas, higher plant capital costs and cost of money; higher gas prices; increased expenditure on electricity networks and costs associated with compliance with environmental policies. Specifically, we documented four scenarios which are outlined in Table 1.

Table 1: Pricing scenarios outlined in The Boomerang Paradox Part I

\begin{tabular}{|c|c|c|c|}
\hline Scenario Name & Gas Price $(\$ / G J)$ & $\begin{array}{c}\text { Carbon Price } \\
(\$ / \text { tonne) }\end{array}$ & $\begin{array}{c}\text { Higher capital costs and } \\
\text { network expenditure }\end{array}$ \\
\hline Low Gas & $\$ 3.60$ & $\$ 0$ & Yes \\
\hline High Gas & $\$ 6.75$ & $\$ 0$ & Yes \\
\hline Low Gas + CO2 & $\$ 3.60$ & $\$ 32.06$ & Yes \\
\hline High Gas + CO2 & $\$ 6.75$ & $\$ 32.06$ & Yes \\
\hline
\end{tabular}

The four scenarios presented in Table 1 were constructed for the purpose of determining whether the variable components of future price increases were the primary or secondary drivers of overall price increases through to FY15. The two variables tested were:

- $\quad$ Gas prices: Our low gas scenario reflects the value of gas given the economic cost of extraction and a fair return on investment. Our analysis of the high gas scenario showed that gas prices may be significantly impacted by the development of an LNG industry on the east coast of Australia with 'LNG netback pricing' likely to result in an almost doubling of gas prices by FY15.

- $\quad$ Carbon pricing: While no significant carbon reduction regime currently exists, there is significant discussion within Australia about the adoption of a broad based emissions trading scheme.

\footnotetext{
${ }^{3}$ The concept of 'fuel poverty' should not be confused with 'energy poverty' - the latter being associated with developing countries where parts of the population are unable to access electricity at any price due to inadequate infrastructure. Fuel poverty on the other hand describes a situation where the combined energy costs of a household exceed $10 \%$ of income.
} 
Our projections for end-user electricity prices under the four scenarios are presented in Figure 1.

Figure 1: Comparative analysis of annual electricity costs in FY08 and FY15

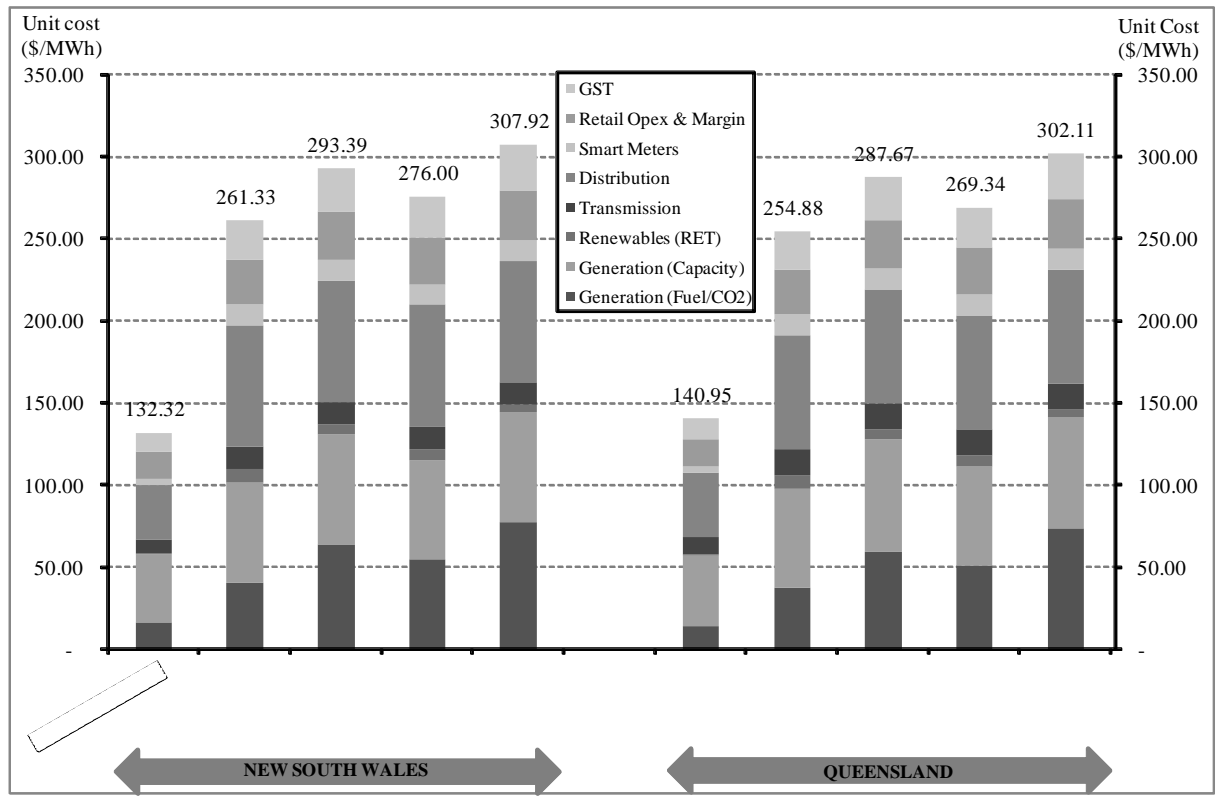

Our price projections clearly show that electricity prices in NSW and QLD are likely to increase by: between $96 \%$ and 133\%; and between $81 \%$ and $116 \%$ respectively in FY15 relative to FY08. The conclusion to be drawn is therefore quite clear, prices are likely to nearly double over this time period irrespective of the introduction of a carbon price and a shift to LNG netback gas pricing. To explain more clearly the nature of the cost shock, Figure 2 focuses on the FY15 High Gas Scenario excluding carbon taxation and undertakes a building-block analysis of electricity tariffs. Note that the largest single contribution to FY15 tariffs is Generation (Fuel) at $\$ 46.25 / \mathrm{MWh}$ or $33.8 \%$. Next is Distribution charges and smart meters, which accounts for a $32.5 \%$ increase. The total increase from FY08 to FY15 is $102.3 \%$ under the High Gas Scenario, compared to the CPI increase of $19 \%$ for the same period. It seems uncontentious to suggest that with such a substantial gap, there is likely to be an increase in the number of households having difficulties paying their quarterly electricity bills. 
Figure 2: Buildup of electricity costs between FY08 Base and FY15 High Gas Scenario

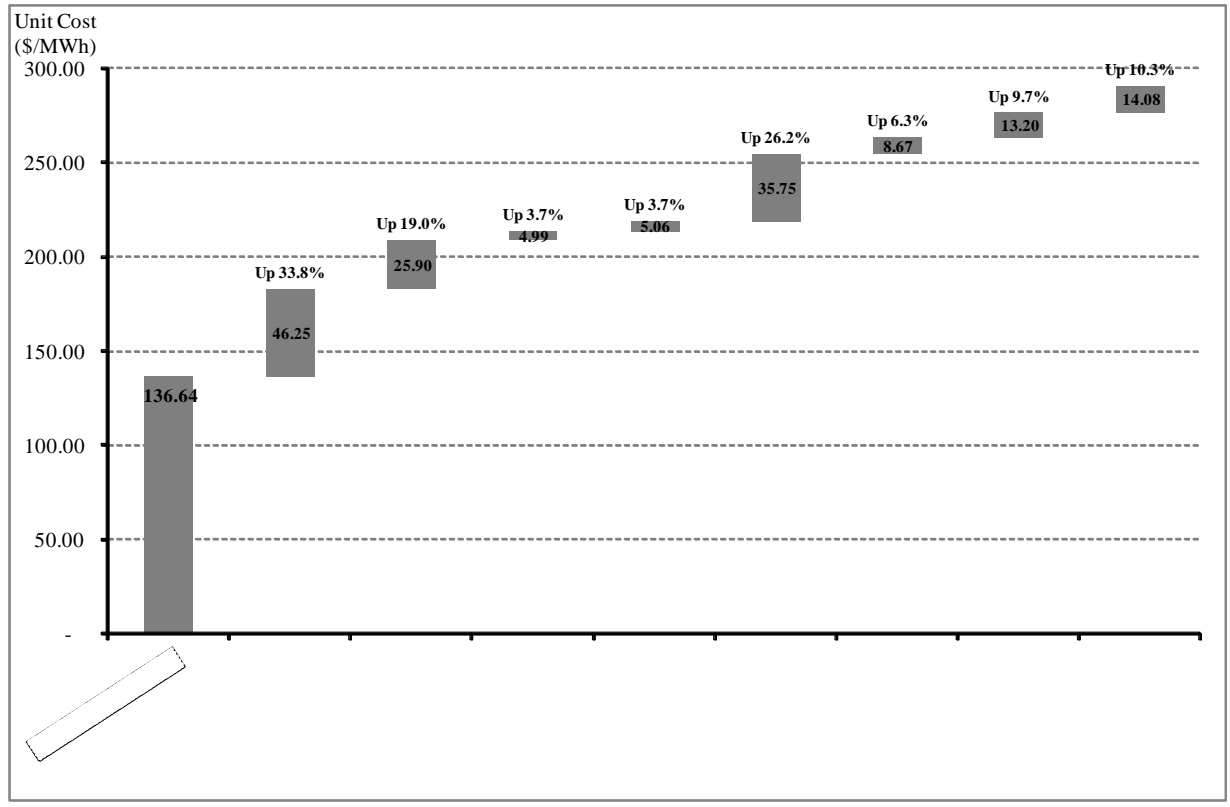

\section{Defining Fuel Poverty in Australia}

A consumer is said to be experiencing fuel poverty if they spend more than $10 \%$ of income on energy to maintain an adequate household. In the UK, this is defined specifically as expenditure to maintain an adequate level of warmth within the dwelling. This definition requires researchers to estimate expenditure on energy rather than use actual energy expenditure per household. The UK Government has established a specific UK Fuel Poverty Strategy and progress against goals is reported annually. The ultimate aim of the UK Fuel Poverty Strategy is that by 2018, no household in the UK should live in fuel poverty. Despite the focus of governments for the best part of a decade, the number of households experiencing fuel poverty in the UK has increased from 2 million to 4 million since 2004 (DECC, 2009).

Fuel poverty in this study is defined as a condition in which a household actually spends more than $10 \%$ of its income on energy, with our focus being on the all-electric housing stock for ease of analysis. This is different to the definition of fuel poverty adopted by the UK. A key limitation of the UK definition is that it prescribes a level of ambient temperature within a dwelling. This ignores household options for warming and cooling unrelated to consuming energy (e.g. putting on an additional layer of clothing in winter). Rather than estimating household expenditure given ambient temperature targets, this article utilises actual energy consumption spending and real incomes to determine the proportion of household income spent on energy. As such, the measure of fuel poverty provided in this article could be argued to be more reflective. For a more comprehensive study on fuel poverty, expenditure on all forms of energy (including natural gas) would need to be incorporated. ${ }^{4}$

${ }^{4}$ NSW and QLD have been selected for analysis in this study due to the lower penetration of natural gas for domestic heating and water heating. By focusing on states with a higher reliance on electricity, we believe we are better placed to provide conclusions about the likely incidence of fuel poverty. 


\section{The Creation of Fuel Poverty in Australia}

To determine the impact on different households, we have utilised disposable income data broken into quintiles published by the Australian Bureau of Statistics for NSW and QLD. ${ }^{5}$ We have then estimated the proportion of disposable household income spent on electricity using our price estimates for FY08 and FY15 in Section $2^{6}$. Figure 3 outlines the proportion of disposable income spent on electricity in FY08 by household quintile. Even in the lowest quintile, the proportion spent on electricity is less than the $10 \%$ threshold required to define a household as fuel poor. Figure 3 demonstrates that as incomes increase, the proportion of household expenditure on energy declines. This is not surprising given electricity is an essential service rather than a luxury good. The implication for studying fuel poverty is that it is only the bottom quintile which requires specific consideration by policy makers. Other households should be able to adjust their budgets accordingly and absorb price increases.

Figure 3: Proportion of disposable household income spent on electricity in FY08

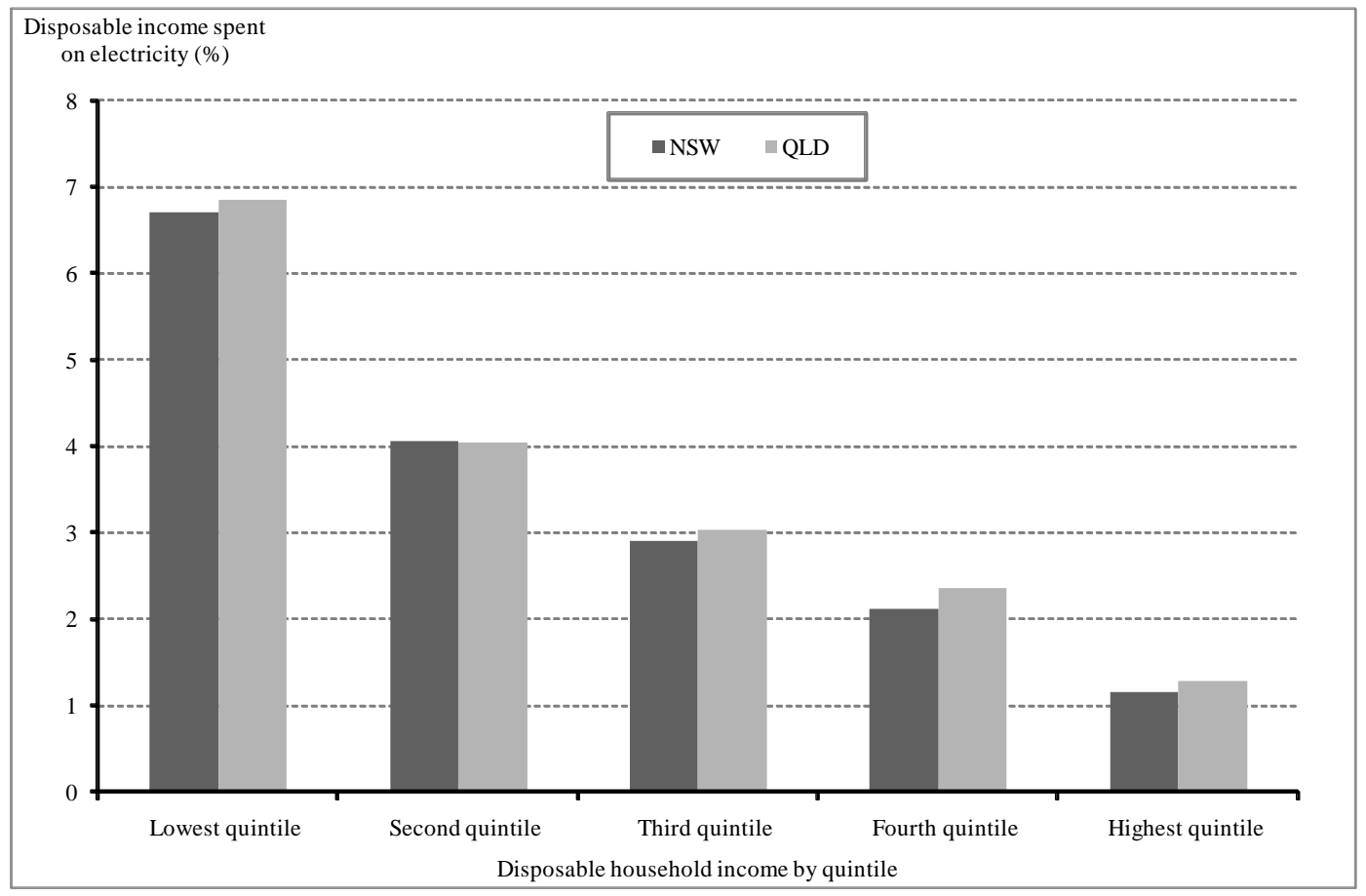

To further understand why the lowest quintile income earners are more susceptible to fuel poverty, it is worth noting some of the underlying characteristics and drivers of energy demand of individual households in specific income quintiles:

- $\quad$ Underlying Minimum Household Demand: Irrespective of household wealth or disposable income, there is an underlying minimum household demand for electricity that relates to the essential service nature of the commodity. All households utilize electricity (or an energy substitute) for basic survival requirements including warmth, cooking and lighting.

- $\quad$ Appliance use: 2008 data for Australian households indicates that 67\% used spatial cooling and $77 \%$ used spatial heating. Spatial heating/cooling comprises $41 \%$ of household energy costs. Water heating accounts for $24 \%$ and other appliances about $13 \%$. Worthy of

\footnotetext{
${ }^{5}$ We have used actual disposable income survey data published by the ABS for FY08. To produce estimates for FY15, we have increased FY08 average quintiles based upon the average growth for the preceding 7-year period. See ABS at http://www.abs.gov.au/AUSSTATS/abs@.nsf/DetailsPage/6523.02007-08?OpenDocument

${ }^{6}$ We have kept average household usage constant for this analysis at 7.8 MWh per household per annum
} 
mention is the fact that plasma televisions consume almost three times more power than older versions. ${ }^{7}$

Figure 4 outlines the increase in electricity expenditure for the lowest quintile across the pricing scenarios for FY15 in NSW and QLD. Under the Low Gas scenario, the average household in the lowest quintile would be spending 9.6\% of disposable income on electricity in FY15, and about $10.2 \%$ in the Low Gas+CO2 scenario. ${ }^{8}$ In the High Gas scenario, this increases to $10.8 \%$ and without a carbon price and $11.4 \%$ in the High Gas+CO2 scenario. Based upon this analysis, the average household in the lowest quintile of household income distribution would be experiencing fuel poverty in FY15 in all but the Low Gas scenario.

Figure 4: Disposable household income spent on electricity in FY15 (lowest quintile)

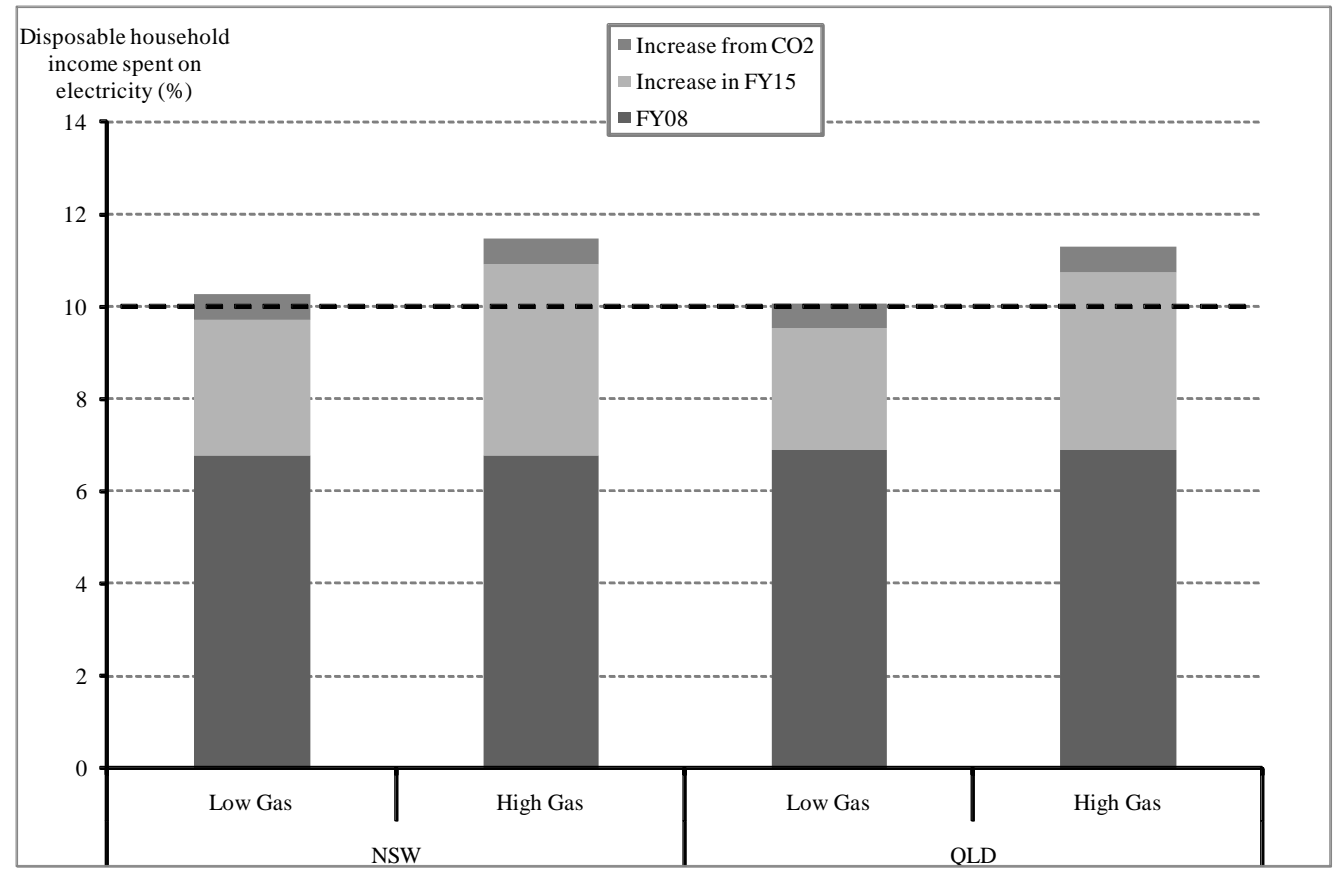

However, the impacts on individual households within the lowest quintile will not be uniform they will be dependent upon actual usage. Through logical deduction, one might expect that low income households consume less than average income households. However, empirical data indicates otherwise. A survey of electricity usage completed by the Independent Pricing and Regulatory Tribunal on NSW households provides the appropriate insight into the dispersion of electricity consumption in the lowest quintile. Table 2 outlines the consumption patterns of households with a gross income of less than $\$ 31,000$. For the purposes of this study, we have assumed that these consumption patterns are broadly reflective for the lowest household disposable income quintile.

Table 2: Consumption patterns of lowest household disposable income quintile (NSW)

\begin{tabular}{lcccc}
\hline Consumption Band & $<4,000 \mathrm{kWh}$ & $4,001-8,000 \mathrm{kWh}$ & $8,001-12,000 \mathrm{kWh}$ & $>12,000 \mathrm{kWh}$ \\
\hline$\%$ of Households & $36.5 \%$ & $30.9 \%$ & $20.6 \%$ & $12 \%$ \\
$\%$ Above Mean Consump & - & - & $33.3 \%$ & $60 \%$ \\
\hline
\end{tabular}

\footnotetext{
${ }^{7}$ See ABS at http://www.abs.gov.au/AUSSTATS/abs@.nsf/Lookup/4102.0Main+Features80March\%202009 for details of appliance use.

${ }^{8}$ Note that under the Government's Carbon Pollution Reduction Scheme (CPRS), households would have qualified for rebates through the taxation system that would have more than offset the cost of carbon. Those rebates have not been considered here.
} 
Table 2 demonstrates that a substantial proportion of low-income households are very high users of electricity. Of the lowest income households, 20.6\% consume between 8,001 kWh and 12,000 $\mathrm{kWh}$ and $12 \%$ consume more than $12,000 \mathrm{kWh}$. These two bands represent consumption of $33.3 \%$ and $60 \%$ greater than the mean consumption patterns. It is clear that this significant distribution of consumption patterns within the lowest disposable income quintile of households is likely to have a profound impact on whether households are likely to experience fuel poverty. An analysis of AGL Energy's own customer hardship program ("Staying Connected Program") indicates that those customers tend to be lower income households, living in lower value housing stock, most likely with 3-4 people in the home, and importantly, with consumption patterns skewed in the medium to high range (i.e. $7,000+\mathrm{kWh}$ pa). Figure 5 outlines the proportion of disposable income spent on electricity by the lowest quintile households:

Figure 5: Disposable income spent on electricity by lowest quintile households by consumption

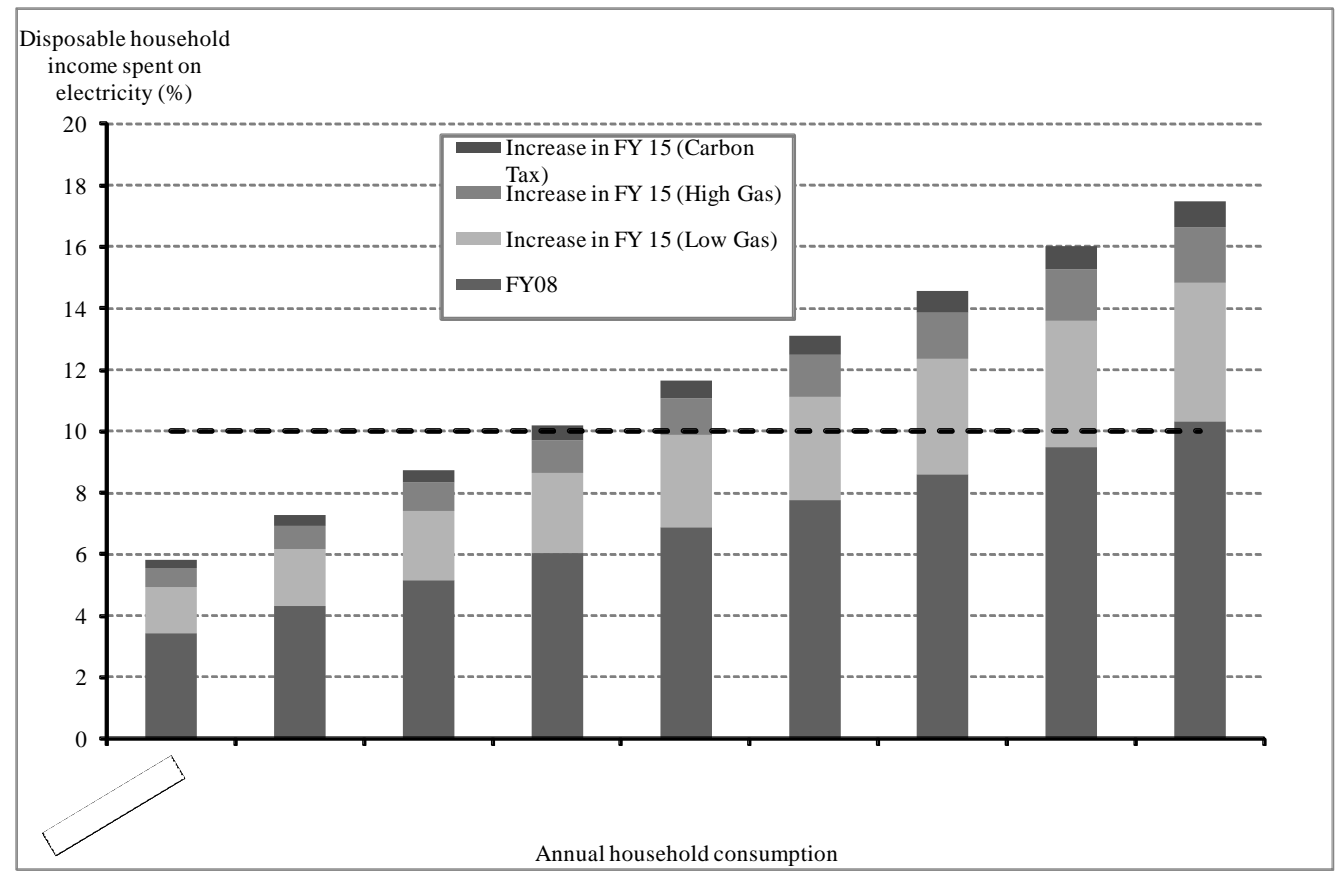

Figure 5 demonstrates that low-income households using 8,000 kWh per year or more are likely to experience fuel poverty in FY15 under any scenario. So how large is this problem? Based upon our estimate of households within this band of consumption, it is likely that around 33\% of low-income households, or 6.6\% of total NSW and QLD households will experience fuel poverty by FY15. As Table 3 notes, this amounts to 343,902 households in NSW and QLD.

Table 3: Estimated number of households experiencing fuel poverty in FY15

\begin{tabular}{|c|c|c|c|c|c|}
\hline State & $\begin{array}{r}\text { FY08 } \\
\text { Households* }\end{array}$ & $\begin{array}{l}\text { F'cast annual } \\
\text { growth rate }\end{array}$ & $\begin{array}{r}\text { FY15 } \\
\text { Households }\end{array}$ & $\begin{array}{r}\begin{array}{r}\text { Fuel Poverty } \\
\text { ratio }\end{array}\end{array}$ & $\begin{array}{l}\text { Est. households in } \\
\text { Fuel Poverty FY } 15\end{array}$ \\
\hline NSW & $2,977,603$ & $1.25 \%$ & $3,247,401$ & $6.60 \%$ & 214,328 \\
\hline QLD & $1,670,789$ & $2.33 \%$ & $1,963,234$ & $6.60 \%$ & 129,573 \\
\hline TOTAL & $4,648,392$ & & $5,210,635$ & & 343,902 \\
\hline
\end{tabular}

* Source: ESAA (2009). ^Equivalent to the average annual growth rate between FY04-FY08.

\section{Policy Implications}

In The Boomerang Paradox Part I, we touched seldom and lightly on interim tariffs between FY08 and FY15. Electricity tariffs have already commenced their upward march. In NSW for 
example, about $\$ 65 / \mathrm{MWh}$ will have been added to our FY08 base case in just two years (i.e. more than half of our envisaged price increase). With $6.6 \%$ of households projected to be experiencing fuel poverty by FY15, it would seem logical to accelerate policy debate in order to reduce the incidence of fuel poverty ahead of the significant cost increases projected in this study.

Before discussing our policy recommendations, it would be misleading of us to imply that a policy vacuum currently exists. For example, the Energy Minister in QLD recently noted that for electricity consumers in that state, a $\$ 190$ rebate policy is available for senior card holders, a home emergency energy assistance scheme provides up to \$720 per household per year for two years, concessions exist for those on life-support machines and a 'ClimateSmart' home service is available to help households reduce energy demand (DEEDI, 2010). NSW has similar supporting policies. And at the Federal level, a carbon tax would also be accompanied by household support at a level designed to be at least equivalent to the cost impact of the tax. But the policies at the state level are designed for current circumstances, not future circumstances. Our analysis of policy implications focuses on the symptom (i.e. fuel poverty) and the cause (i.e. rising electricity tariffs).

\section{- Fuel Poverty Policies}

On fuel poverty, to be sure, the funding of any such policies should be considered in light of the incremental and predictable increase in Goods and Services Tax (GST) receipts collected through higher energy prices. In our analysis, we indicated that GST would increase from about \$12.00/MWh in FY08 to \$23.00-\$28.00/MWh in FY15 depending on the scenario. In FY08, our estimation of GST receipts from electricity consumers in NSW and QLD amounts to \$410 million. By FY15, GST receipts would rise to \$880-\$1041 million. ${ }^{9}$ Accordingly, incremental GST revenue to the Federal Government will increase by an inflation-adjusted $\$ 393-\$ 553$ million. ${ }^{10}$ This provides a starting context. If, for example, the inflation-adjusted windfall GST gains were directed entirely to lowest quintile households, it would cover $70 \%$ of their electricity accounts - clearly eliminating fuel poverty. Of course, it could also over-correct the problem and lead to overconsumption.

Any redesign of household assistance needs to be properly focused. A critical failure of government assistance programs related to eliminating fuel poverty is their inappropriate method of payment. As an example, the proposed assistance for low-income households to compensate for higher energy bills as a result of the introduction of the Carbon Pollution Reduction Scheme was to be provided in lump sum payments. ${ }^{11}$ Assistance should be provided in a form which reflects the intent of assistance. For example, payments could be made by Government direct to household bills (via their host energy retailer). This would ensure that assistance meets the intended purpose.

Where assistance programs are already in place for low-income consumers, assistance might be redesigned to reflect electricity consumption seasonality, being paid in four unequal amounts directly on electricity bills rather than the current system of annual rebates, often by cash.

Alternatively, bill smoothing could be actively promoted by government, and readily supplied by energy retailers. Of course, bill shock would clearly be minimized even further, and household budgetary planning greatly enhanced, by switching to monthly electricity account processing.

\footnotetext{
${ }^{9}$ ESAA (2009) reported that customer numbers in NSW and QLD were $2.977 \mathrm{~m}$ and 1.671 million, respectively. Whole of region electricity consumption (including non-metro areas) averaged 7.23MWh per household. Customer numbers were projected forward at annual growth rates of $1.25 \%$ and $2.33 \%$ for NSW and QLD respectively, which is equivalent to the average annual growth rate between FY04-FY08.

${ }^{10}$ Adjusting the $\$ 410 \mathrm{~m}$ GST collected in FY08 at CPI to FY15 amounts to $\$ 488 \mathrm{~m}$.

${ }^{11}$ Commonwealth Government, Carbon Pollution Reduction Scheme: Australia’s Low Pollution Future, December 2008
} 
The experience of outsourced billing enterprises is clear on this - the incidence of account default is minimized substantially via monthly billing.

There would also seem to be merit in reviewing policies which governs the availability of household credit for energy consuming appliances. Around $10 \%$ of transactions completed by individuals with a personal income below $\$ 20,000$ pa are financed via some form of credit and $35 \%$ of all retail transactions worth more than $\$ 500$ are settled using credit cards or another form of household credit (Simon, Smith and West, 2009). Given most of the significant energy consuming appliances in the home are likely to cost more than $\$ 500$ (e.g. fridges, televisions, air conditioners and heaters), preferential financing might be made more available for highly efficient energy appliances, and eliminated for lower cost, lower efficiency models. As Hahn (1999, p.3) previously observed:

...large expenses such as the purchase of furniture or white-goods are impossible to manage without incurring debt if the income level does not allow for savings, challenging the accepted notion that consumer credit is used to satisfy wants rather than needs...

Access to essential energy consuming consumer capital goods requires a level of 'essential service credit' to be made available to households most likely to experience fuel poverty (Howell and Wilson, 2005). The QLD government's current Emergency Energy Scheme might provide a useful template, and expanded to incorporate such credit facilities.

There is also a need to broaden the Shared Responsibility model associated with energy customer hardship. At present, energy retailers, state governments and community organisations provide support for consumers experiencing hardship related to an inability to pay energy bills. However, energy appliance manufacturers and appliance retailers have a role to play in determining whether a household may become fuel poor. The marketing of cheap, energy inefficient appliances 'lockin' an inability to pay higher energy bills as the appliance stock contained within the average household has a relatively long tenor (e.g. air conditioners and fridges 10-15 years, other electric appliances such as TV's and computers 5 years). In this context, it is worth considering a shared responsibility model where manufacturers and retailers of energy consuming appliances are required to provide preferential pricing to customers in hardship. This could be implemented through amendments to consumer credit codes to ensure that retailers of energy consuming appliances restrict access to credit (in all forms) to only the most energy efficient appliance.

\section{- Electricity Market Policies}

Policies relating to the root cause of fuel poverty (i.e. rising tariffs) are more complex and will inevitably involve non-trivial political commitment. Because rising peak demand is at the core of the electric cost shock, which in turn causes the requirement for additional generating systems and network augmentation and a deterioration in load factors, reducing peak growth rates should be a 'policy fundamental'.

The initial knee-jerk reaction from governments may be to regulate prices down in response. But an important lesson exists in relation to artificially suppressing electricity price shocks; in arguably one of the most important academic works on Demand Response, Reiss and White (2008) found that by shifting from cost-reflective pricing of US\$230/MWh to an artificially suppressed electricity tariff of US\$140/MWh led to an 8\% surge in household system peak demand in the San Diego area. The lesson here is clear - suppressing price may reduce electricity bills initially, but over the longer term it will inevitably aggravate the problem of peak demand. The experience of Western Australia provides a similar warning. As noted in Simshauser, Molyneux and Shepherd (2010), after artificially suppressing residential electricity prices for 11 
years, restoring cost reflective pricing would entail tariff increases of 116 percent over three years from 2009, with the State Government being forced to inject $\$ 780$ million of taxpayer funds to support its financially distressed electricity industry in 2008.

The regulated ceiling or safety net electricity tariffs in NSW and QLD have historically been set sub-optimally relative to industry LRMC. Economic theory has long been relaxed with the notion that a mis-priced commodity will lead to over-consumption and a distortion of resource allocation within the economy. More recently, base tariff levels have been rectified in both states with FY10 decisions and the current FY11 determinations largely considered as cost reflective tariffs. Clearly this needs to continue. But the better policy outcome is to deregulate price to ensure this remains the case (whilst maintaining regulation over monopoly network prices). Energy companies, with their vast expertise in managing price risks in the highly volatile wholesale markets can barely forecast outcomes 12 months ahead. It is beyond belief that a regulator might do a better job. The state governments of QLD and NSW need to work towards implementing their commitments under the Australian Energy Market Agreement to remove price regulation. ${ }^{12}$ The proviso here is that competition has been demonstrated as effective in the respective retail market. Based on the latest global rankings in Lewis and Grey (2008), NSW and QLD clearly qualify as highly competitive retail markets being ranked in the top 10 globally.

A roll-out of smart meters and a shift to time-of-use and critical peak-pricing tariff structures along with in-home energy displays provides the best known way to reduce system peak demand. The quintessential applied economic research in this field by Faruqui et al. (2009) is clear on this. Certainly incremental GST revenues should be more than adequate to finance 300,000 in-home displays for households most at risk. However, for very low consumption households (consuming less than say 3MWh pa), constraints around the use of time-of-use and critical peak pricing tariffs would seem entirely appropriate for consumer protection reasons. At low levels of household consumption, it is most unlikely that prevailing demand could be reduced, or shifted, and thus the costs of interval metering and time-of-use tariff structures are unlikely to outweigh the benefits.

A shift to interval metering and time-of-use pricing may also initially aggravate the problem of energy affordability with some consumers because with the current accumulation or 'dumb' meters, prices are averaged and by implication, extensive cross-subsidies exist within ${ }^{13}$ and across customer classes. But until such pricing structures exist, poor utilization of capital intensive generating systems and network assets will persist and inevitably deteriorate.

The main contributions to the price shocks envisaged in our analysis come from the unit cost of gas (up 33.9\%), network charges (up 27.9\%) and generation plant costs (up 19.3\%). Unit gas costs will invariably reflect prevailing supply and demand conditions; policies aimed at making the initial investment task easier such as streamlined approval processes, faster release of new tenements and acreage can be expected to enhance supply; any policy aimed at suppressing the market clearing price (e.g. domestic CSG reservation policies) may be met with initial success, followed by longer-term over-consumption and under-investment in new production capacity. Ultimately, the supposed cure would lead to a result far worse than the initial disease.

Rises in network charges beyond FY15 would be best arrested by smart metering and time-of-use tariffs; but also the privatization of the government owned NSW and QLD network companies. Mountain and Littlechild's (2009) insightful comparative analysis of capital expenditure and price increases in the VIC and British (privately owned) network businesses were found to be

\footnotetext{
${ }^{12}$ Australian Energy Market Agreement signed by all States and the Commonwealth, 2006, p.29

${ }^{13}$ For example, the infrastructure costs associated with households with large energy consuming equipment operating at times of peak demand (e.g. pool pump, air conditioning) are effectively being spread across the entire customer base.
} 
substantially less ${ }^{14}$ than their public sector counterparts in NSW (and by implication, QLD). ${ }^{15}$ One logical explanation of this is that private sector participants are heavily capital constrained, whereas publicly owned network businesses are limited to paying equity distributions from accounting profits.

This is important. The issue here is that private sector entities are able to initiate legal and taxrelated structures which enable shareholder loans to be established, thus enabling higher dividend payments to equity holders. For example, Victorian Network business SP Ausnet paid dividends of \$245.1 million during FY09 whilst reporting an accounting Net Profit after Tax (NPAT) of just \$146.9 million. Depreciation charges amounted to \$209.1 million which explains how the differential is funded from a cashflow perspective. ${ }^{16}$ Public sector enterprises on the other hand are subject to strict financial guidelines which prohibit the payment of dividends beyond reported accounting profits rather than cash profit. For example, NSW distributor Energy Australia posted an accounting NPAT of $\$ 231$ million but paid dividends of just $\$ 173$ million. The vast accounting depreciation charges of \$293 million have therefore trapped cash within this public business and others like it. ${ }^{17}$ Besides which, any attempt to raise dividend payments to the State Government owners is inevitably met with harsh, politically-charged (and usually mis-guided) criticism, in spite of the obvious disconnect with private sector practice. The end result is that these publicly owned businesses are literally awash with cash available for investment, and any reinvestment is rewarded with the private sector's post-tax cost of capital despite having no federal tax liability. ${ }^{18}$

On the cost of generation plant, Australia has no manufacturing capability and is therefore a pure price-taker and subject to global turbine price trends. Similarly, as a country with a severe structural reliance on foreign capital (foreign capital accounting for more than $60 \%$ of all invested funds in Australia), the cost of capital used to construct plant is primarily beyond the control of government (Simshauser, 2010). However, credit spreads in merchant plant of 350 basis points with the tenor of debt currently at 3-5 years compares poorly to recent monopoly-regulated network debt capital raisings with spreads 160 basis points over swap, and $7 \frac{1}{2}$ year tenors. ${ }^{19}$ Generators have typically been able to secure identical debt tenors, with marginally higher spreads of 120 basis points compared to network spreads of 60-80 basis points. Clearly, the current situation of short tenors and dramatically higher spreads reflects perceived regulatory risk in the deregulated NEM market. Removal of regulated retail prices and clarity over carbon policies will invariably lead to a reduction in the current 'merchant funding gap'.

\section{Conclusions}

The purpose of this article and its predecessor, The Boomerang Paradox Part I, was to produce an end-to-end analysis of the cost pressures building up in the electricity supply chain, and to identify policy settings which could defuse the propensity for fuel poverty to emerge. Our findings are clear; electricity prices in NSW and QLD have the potential to rise from about \$135/MWh in FY08 to \$255/MWh+ in FY15. Our worst case scenario breached \$300/MWh. We could not identify a single element in the electricity cost stack that was not increasing at a rate faster than prevailing inflation expectations. Australians will slowly become accustomed to this;

\footnotetext{
${ }^{14}$ See especially Figures 6-9 on pages 20-21 in Mountain and Littlechild (2009).

${ }^{15}$ Although the article was met with criticism from industry and regulatory authorities on the grounds of Great Britain's higher population density, subsequent analysis revealed that the density in the Sydney Metro network areas (where the majority of capex in NSW is being spent) is actually marginally higher than the median British network population density.

${ }^{16}$ See http://www.sp-ausnet.com.au for details of the FY09 SP Ausnet Annual Report.

${ }^{17}$ See http://www.energyaustralia.com.au for details of the FY09 Energy Australia Annual Report.

${ }^{18}$ Government Owned Corporations pay a tax equivalent to their State Government owners. Thus the apparent return to Governments from network investments is enhanced because corporate taxes are taken out twice; once as a payment to the State Government, and once in the form of post-tax network returns on capital.

${ }^{19}$ See http://www.sp-ausnet.com.au/CA2575630006F222/Lookup/ASX2010/\$file/SPNAUDBondIssue18Mar10.pdf for details of the recent SP Ausnet bond issue.
} 
in the National 2009 September Quarter inflation results, price rises from utilities were noted for their contribution to the national inflation rate following the tariff increases at the start of the new financial year. ${ }^{20}$ However, we were also able to identify a funding source which is more than sufficient to circumvent the most adverse effects.

Most fundamentally, our results indicate that under any of our scenarios in which Combined Cycle Gas Turbine plant sets the industry LRMC, and consumers are charged according to load factor, fuel poverty is likely to emerge. Based on the survey data from IPART (2006) it appears that about 214,000 NSW households and 130,000 QLD households will fall into this category.

Our policy analysis reveals that incremental GST collections from electricity accounts are more than adequate to eliminate fuel poverty. Our recommendations focuses on access to efficient electric appliances, credit policies, and a widespread shift to smart meters and time-of-use tariff structures - the latter of which initially may agitate the problem in some cases before gains emerge - and in-home displays for fuel poor households.

Continuously rising household income and low cost power led to rising residential floor-space and vast increases in usage of electric appliances including air conditioners. Peak demand has risen exponentially. The cost and consequences of the requirement for capacity augmentation are gradually being revealed, and it is likely to cause fuel poverty. This is the Boomerang Paradox.

\section{References}

DECC: Department of Energy \& Climate Change, (2009), “The UK Fuel Poverty Strategy $7^{\text {th }}$ Annual Progress Report 2009”, DECC, London. Available at http://www.decc.gov.uk/. Accessed 13 April 2010.

DEEDI: Department of Employment, Economic Development and Innovation, (2010), "Submission to the Queensland Competition Authority: response to the draft decision on the Benchmark Retail Cost Index for electricity 2010-11”, DEEDI, Brisbane. Available at www.qca.org.au. Accessed 17 February 2010.

DEWHA: Department of Environment, Water, Heritage and the Arts, (2009), “Energy use in the Australian residential sector: 1986-2020”, DEWHA, Canberra. Available at http://www.environment.gov.au/. Accessed 20 February 2010.

ESAA: Energy Supply Association of Australia, (2009), ElectricityGas Australia, ESAA Publication, Melbourne.

Faruqui, A., Hledik, R. and Sergici, S. (2009), “Piloting the smart grid”, The Electricity Journal, 22(7): 5569.

Hahn, B. (1999), “No Interest Loans: What are they?”, NCOSS No Interest Loans Conference, Sydney.

Howell, N., and Wilson, T. (2005), “Access to consumer credit: the problem of financial exclusion in Australia and the current regulatory framework", Macquarie Law Journal, Volume 5. Available at http://www.austlii.edu.au/au/journals/MqLJ/2005/7.html\#Heading18

IEA: International Energy Agency, (2005), "Energy Policies of IEA Countries - Australia 2005 Review”, IEA Publication, Paris. Available at http://www.iea.org/textbase/nppdf/free/2005/australia2005.pdf

Lewis, P. and Grey, P. (2010), "Utility customer switching", Vaasaett Publication, available at http://www.vaasaett.com/projects/switching-project/.

\footnotetext{
${ }^{20}$ See ABS series 6401.0 media release for September 2009 available at http://www.abs.gov.au
} 
Mountain, B. and Littlechild, S. (2009), "Comparing electricity distribution network costs and revenues in New South Wales and Great Britain”, EPRG Working Paper 0930, University of Cambridge. Available at www.eprg.group.cam.ac.uk

QCA: Queensland Competition Authority, (2005), "Regulation of electricity distribution", QCA Publication, Brisbane. Available at http://www.qca.org.au. Accessed 16 February 2010.

QCA: Queensland Competition Authority, (2007), "Benchmark retail cost index for electricity: 2006-07 and 2007-08”, QCA Publication, Brisbane. Available at http://www.qca.org.au. Accessed 16 February 2010 .

Reiss, P. and White, M., (2008), "What changes energy consumption? Prices and public pressures”, RAND Journal of Economics, 39(3): 636-663.

Simon, J., Smith, K., and West, T. (2009), "Price Incentives and Consumer Payment Behaviour”, RBA Discussion Paper, Reserve Bank of Australia, Sydney.

Simshauser, P. (2010), “Capital adequacy, ETS and investment uncertainty in the Australian power market”, Electricity Journal, Vol. 23, No. 1, pp 67-84.

Simshauser, P., Molyneux, E. and Shepherd, M. (2010), "The entry cost shock and the re-rating of power prices in New South Wales”, Australian Economic Review, Vol. 43, No.2, pp 114-135. 